\title{
Happamien sulfaattimaiden ympäristöriskien vähentäminen: vesistövaiku- tukset ja sopeutumiskeinoja ilmastomuutokseen CATERMASS Life+ - hankkeessa vuosina 2010-2012
}

\author{
Kari-Matti Vuori $^{1}$ ja Tuomas Saarinen ${ }^{2}$ \\ ${ }^{1}$ Suomen ympäristökeskus, Jyväskylän toimipaikka, PL 35, 40014 Jyväskylän yliopisto \\ ${ }^{2}$ Oulun yliopisto, prosessi- ja ympäristötekniikan osasto, PL 4300, 90014 Oulu
}

\section{Tiivistelmä}

Suomessa on happamia sulfaattimaita viljelymaana 100000 - 200000 ha, ja metsätalouskäytössä oleva pinta-ala on tuntematon. Näiden maiden kuivatuksen aiheuttama happamuus- ja metallikuormitus on merkittävästi heikentänyt pintavesien ekologista ja kemiallista tilaa sekä jokien ja rannikkoalueiden kalakantoja. Sulfaattimailta tuleva nykyisinkin suuri ympäristökuormitus ja vesistöhaitat uhkaavat kasvaa entisestään ilmastonmuutoksen seurauksena. Hydrologisten ääriolojen yleistyminen, talvisadannan ja virtaamien kasvu sekä maaperän ja vesistöjen lämpeneminen lisäävät riskejä happamuuden ja metallien huuhtoutumiselle ja ekotoksikologisille haitoille. Korjaaviin toimenpiteisiin ryhtyminen on välttämätöntä vesipolitiikan puitedirektiivin, meristrategiadirektiivin, prioriteettiainedirektiivin, tulvadirektiivin ja luontodirektiivin mukaisten ympäristötavoitteiden saavuttamiseksi.

Suomen ympäristökeskuksen (SYKE) koordinoimana on käynnistynyt vuosina 2010-2012 toteutettava, EU:n Life+-ohjelmasta rahoitettava hanke ilmastomuutoksen aiheuttamien ympäristöriskien vähentämiseksi happamilla sulfaattimailla (Climate Change Adaptation Tools for Environmental Risk Mitigation of Acid Sulphate Soils -CATERMASS). SYKEn lisäksi hankkeen päätoteuttajina ovat GTK, MTT, Helsingin yliopisto, Åbo Akademi sekä Etelä-Pohjanmaan elinkeino-, liikenne- ja ympäristökeskus. Hankkeen tavoitteena on kehittää valmiuksia sopeuttaa happamien sulfaattimaiden maankäyttöä ja vesiensuojelua muuttuvaan ilmastoon.

Varautuminen vesistö-, kalasto- ja biodiversiteettihaittoihin ja niiden torjuntaan vaatii systemaattista tiedon kokoamista ongelma-alueista, happamuus- ja metallialtistuksen skenaarioista, ympäristöriskien luonteesta ja prioriteettikohteista sekä käytettävissä olevista vesiensuojelumenetelmistä ja niiden toimivuudesta muuttuvassa ilmastossa. Hanke on erittäin haastava, sillä ongelmien vähentäminen edellyttää maankuivatuksen ja viljelymenetelmien muuttamista yksityisomistuksessa olevilla maatalousmailla. Ympäristöhaittojen vähentäminen edellyttää laajapohjaista ja osallistavaa riskien hallintaan tähtäävää prosessia, jossa huomioidaan luonnontieteellisten näkökohtien ohella myös sosioekonomiset seikat.

Asiasanat: happamat sulfaattimaat, vesien ekologinen tila, ympäristöriskit, ilmastomuutoksen sopeutumiskeinot

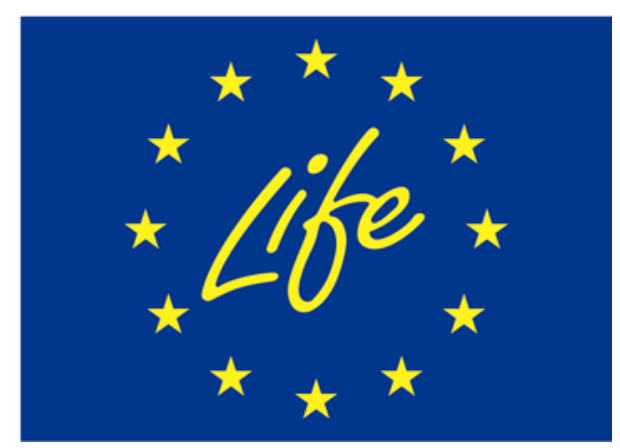




\section{Johdanto}

Ilmastomuutoksen myötä valuma-alueiden hydrologiassa ja maaperäprosesseissa tapahtuu muutoksia, jotka voivat lisätä maankäytön ympäristöriskejä. Erityisenä huolenaiheena ovat geokemialliset anomaliat, kuten poikkeuksellisen korkeita raskasmetalleja sisältävät maa- ja kallioperätyypit. Kaivosalueilla metallianomalioiden aiheuttamat ongelmat viljelykasveille on tunnettu jo pitkään (mm. Rosen ym. 1978) ja niiden happamat, toksiset valumavedet ovat merkittävä vesistöhaitta eri puolilla maailmaa. Kaivosalueiden vesistöissä merkittävimmät ympäristöriskit liittyvät usein sulfidien tehokkaaseen hapettumiseen ja poikkeuksellisiin tulviin (Lin ym. 2007). Vastaavan kaltaisen ympäristöongelman muodostavat happamat sulfaattimaat (HS-maat), joiden määrä ja haittavaikutukset ovat Suomessa merkittäviä (Palko 1994, Fältmarsch ym. 2008).

Useissa länsirannikkomme vesistöissä HS-maiden maankuivatuksen aiheuttamat korkeat metallipitoisuudet ja happamuus ovat merkittävästi vaurioittaneet vesien ekologista ja kemiallista tilaa sekä kalakantoja (Fältmarsch ym. 2008, Vuori 2009). Tässä esityksessä tavoitteenamme on tarkastella seuranta-aineistojen perusteella happamien sulfaattimaiden vesistövaikutusten yhteyttä ilmastomuutoksen kannalta relevantteihin muuttujiin. Toisena tavoitteena on tarkastella millaisia sopeutumiskeinoja HSmaiden ympäristöriskien vähentämiseksi on käytettävissä ja kuinka vuoden 2010 alusta käynnistynyt Life+-hanke "Climate Change Adaptation Tools for Environmental Risk Mitigation of Acid Sulphate Soils -CATERMASS" pyrkii edistämään näitä sopeutumiskeinoja.

Merkittävin ekotoksikologinen haitta HS-maiden valumavesistä aiheutuu tilanteista, joissa vesistössä esiintyy lyhyt- tai pitkäkestoisesti sekä korkeita metallipitoisuuksia että alhaisia pH-arvoja (alle pH 5.5). Nämä tilanteet ovat yleisimpiä tulvakausina. Ilmastomuutoksen on ennustettu lisäävän tulvia ja erityisesti talvisadantaa ja -virtaamia (Silander ym. 2006). Lisäksi kuivien jaksojen on ennakoitu yleistyvän, mikä tehostaa pohjaveden pinnan laskua ja sulfidisavikerrosten hapettumista. Kalakuolemia onkin esiintynyt HS-maiden jokivesissä nimenomaan kuivia kesiä seuranneina sateisina syksyinä ja talvina tai runsaiden kevättulvien yhteydessä. Myös Österholm \& Åström (2008) ovat esittäneet, että ilmastomuutoksen myötä HS-maiden vesistöhaitat voivat yleistyä.

Hypoteesimme tässä tutkimuksessa on, että maksimivirtaamat erityisesti syys-talvikaudella alentavat jokivesien pH-minimejä ja nostavat metallipitoisuuksia. Toki on huomattava, että happamia valumavesiä huuhtoutuu vesistöihin myös muina vuodenaikoina. Laajasti ottaen vesistövaikutusten luonne riippuu sulfidisavikerrosten laadun ja määrän, sääolojen, maankäyttömuotojen, viljely- ja ojituskäytäntöjen sekä valuma-alueen ja vastaanottavan vesistön ominaispiirteiden keskinäisistä yhdistelmistä.

\section{Aineisto ja menetelmät}

Kokosimme SYKEn HERTTA-ympäristötietojärjestelmästä seuranta-aineiston länsirannikon suurten jokivesien pH- ja metallianalyyseistä (esimerkkeinä tässä Cd ja Zn) vuosina 1961-2007. Metallien osalta riittävä aikasarja oli käytössä vain Kyrönjoesta, kun taas $\mathrm{pH}$-mittauksia oli kattavasti useasta HS-maiden jokivesistöstä (Kyrönjoki, Lapuanjoki, Lestijoki, Kalajoki, Siikajoki). Aineistosta laskettiin vuotuiset ja vuosijaksottaiset (kevät, kesä, syksy-talvi) pH:n mediaanit ja minimit sekä metalleille mediaanit ja maksimit. Tässä keskitymme $\mathrm{pH}$ :n osalta vain minimiarvojen tarkasteluun. Vedenlaatua selittäviksi tekijöiksi poimimme HERTTAn hydrologisesta rekisteristä virtaamatiedot, joista laskettiin mediaanit ja maksimit em. vuosille ja vuosijaksoille. Vedenlaadun vaihtelua selittävinä tekijöinä käytimme myös Ilmatieteen laitoksen tietokannoista koottuja tietoja kunkin valuma-alueen vuotuisesta keskilämpötilasta ja -sadannasta. Lisäksi laskimme keskilämpötilan ja -sadannan minimi-pH:n ja pitoisuushuippujen esiintymisaikoja edeltäneille puolivuotiskausille.

Happamuuden ja metallipitoisuuksien vaihtelun suhdetta virtaamaan, lämpötilaan ja sadantaan tutkimme lineaarisen regression avulla. Selittäville muuttujille tehtiin tarvittaessa logaritmimuunnos normaalijakauman saavuttamiseksi. 


\section{Tulokset}

Maksimivirtaama selitti tilastollisesti erittäin merkitsevästi loka-marraskuun $\mathrm{pH}$-minimejä sekä happamien sulfaattimaiden voimakkaasti kuormittamissa (Kyrönjoki ja Lapuanjoki, $\mathrm{R}^{2}=0,31-0,30$, $\mathrm{F}=22,03-20,31, \mathrm{p}=0,000$ ) että vähemmän kuormittamissa (Lestijoki, Kalajoki, Siikajoki, $\mathrm{R}^{2}=0,49-$ 0,25, F=28,26-15,82, p=0,000) jokivesistöissä. Esimerkiksi voimakkaasti kuormitetussa Lapuanjoessa pH laski korkeammilla virtaamilla hyvin usein alle viiden ja pysyi vain harvoin yli ekologisesti kriittisenä pidetyn tason 5,5 (Kuva 1). Kevään minimi-pH:lla ei havaittu merkitsevää tilastollista yhteyttä virtaamamuuttujiin, mutta se korreloi merkitsevästi HS-maiden jokivaluma-alueiden vuotuisen keskisadannan kanssa $(\mathrm{r}<-0,25, \mathrm{p}=0,05-0,01)$.

Mustasaaren Skatilassa, joka on voimakkaan kuormituksen kohde Kyrönjoen alajuoksulla, ovat kadmiumin ja sinkin pitoisuudet olleet yleisesti ottaen korkeimmillaan syys-talvikausilla (lokajoulukuu, Kuva 2.). Kyseisten kuukausien maksimipitoisuuksia selitti merkitsevimmin kauden minimi$\mathrm{pH}$ sekä kadmiumin $\left(\mathrm{R}^{2}=0,56, \mathrm{p}=0,000\right)$ että sinkin $\left(\mathrm{R}^{2}=0,49, \mathrm{p}=0,001\right)$ osalta. Kadmiumin maksimipitoisuuksia selitti merkitsevästi myös kauden maksimivirtaama $\left(\mathrm{R}^{2}=0,34, \mathrm{p}=0,005\right)$. Yksittäisiä korkeita pitoisuuspiikkejä on esiintynyt myös kevät- ja kesäkausina, mutta havaintojen yläkvartiilien ja mediaanien välisistä arvoista kuvassa 2 ja 3 havaitaan, että tasot ovat loka-joulukuussa korkeimmat.

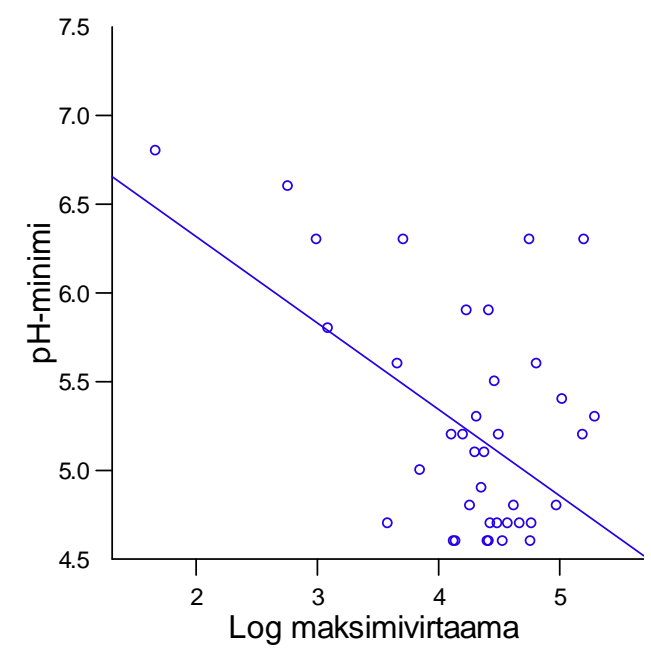

Kuva 1. Loka-marraskuun pH-minimien vaihtelu suhteessa maksimivirtaamiin (logaritimi-muunnos, $\mathrm{m}^{3} / \mathrm{s}$ ) Lapuanjoen alajuoksulla vuosina 1961-2007. Regressioyhtälö: $y=7.487-0.543 x$.

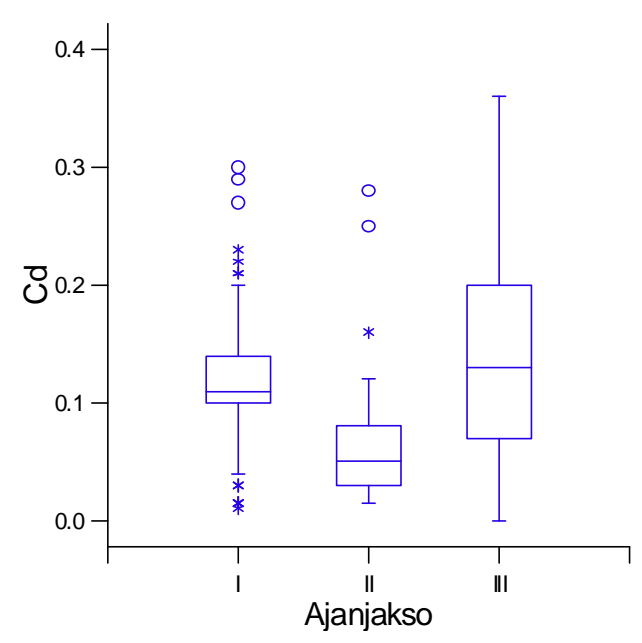

Kuva 2. Kadmiumin pitoisuusvaihtelut ( $\mu$ g Cd/l) Kyrönjoen alajuoksulla (Skatila) vuosina 1986-2007 eri ajanjaksoina (I=maalis-toukokuu, II=kesä-syyskuu, III=loka-joulukuu). 


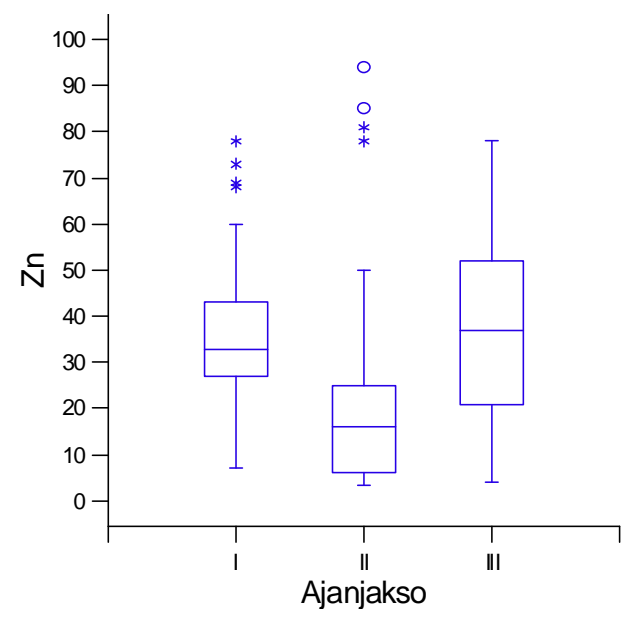

Kuva 3. Sinkin pitoisuusvaihtelut ( $\mu$ g Zn /l) Kyrönjoen alajuoksulla (Skatila) vuosina 1986-2007 eri ajanjaksoina (I=maalis-toukokuu, II=kesä-syyskuu, III=loka-joulukuu).

\section{Johtopäätökset ja CATERMASS-hankkeessa selvitettävät sopeutumiskeinot}

Tuloksemme tukevat sitä yleistä käsitystä, että sulfaattimailta tuleva nykyisinkin suuri ympäristökuormitus ja vesistöhaitat uhkaavat kasvaa entisestään ilmastonmuutoksen seurauksena. Hydrologisten ääriolojen yleistyminen, talvisadannan ja virtaamien kasvu sekä maaperän ja vesistöjen lämpeneminen lisäävät riskejä happamuuden ja metallien huuhtoutumiselle ja ekotoksikologisille haitoille. Mikäli pitkät kuivat jaksot ja niitä seuraavat voimakkaat sateet ja tulvat yleistyvät, kasvaa todennäköisyys hyvin alhaisten $\mathrm{pH}$-jaksojen ja korkeiden metallipitoisuushuippujen esiintymiselle monissa länsirannikon jokivesistöissä. Tästä seuraa pahenevia ekotoksikologisia haittoja ja ekologisen tilan heikkenemistä myös sellaisissa jokivesistöissä joissa HS-maiden haittavaikutukset ovat tähän asti olleet vähäisempiä ja harvemmin toistuvia. Korjaaviin toimenpiteisiin ryhtyminen on välttämätöntä vesipolitiikan puitedirektiivin, meristrategiadirektiivin, prioriteettiainedirektiivin, tulvadirektiivin ja luontodirektiivin mukaisten ympäristötavoitteiden saavuttamiseksi.

Maa- ja metsätalousministeriö ja ympäristöministeriö rahoittivat vuonna 2008 selvityshankkeen, jonka tavoitteena oli kartoittaa happamien sulfaattimaiden aiheuttamien haittojen vähentämiseen liittyvät selvitystarpeet ja laatia ehdotus haittojen vähentämisen suuntaviivoiksi (http://www.mmm.fi/fi/index/ministerio/tiedotteet/090216_happamuus.html). Selvityksen mukaan HS-maiden aiheuttamia haittoja voidaan vähentää useilla eri keinoilla, jotka voidaan jakaa kahden tyyppisiin toimenpiteisiin: a) sulfidien hapettumisen estäminen ja vähentäminen ja b) muodostuneen happamuuden neutralointi ja laimentaminen. Happamuushaittojen korjaaminen jälkikäteen on kallista, joten sulfidikerrosten hapettumisen estäminen on ensisijaisen tärkeää. Selvitystyön pohjalta on tarkoitus laatia kansallinen strategia HS-maiden haittojen torjumiseksi.

Vesistö-, kalasto- ja luontohaittojen vähentäminen edellyttää systemaattista tiedon kokoamista ongelma-alueista, happamuus- ja metallialtistuksen kehityksestä, ympäristöriskien luonteesta ja prioriteettikohteista sekä käytettävissä olevista vesiensuojelumenetelmistä ja niiden toimivuudesta muuttuvassa ilmastossa. Tehtävä on erittäin haastava, sillä ongelma-alueet ovat yksityisessä omistuksessa olevaa maatalousmaata, joilla ongelmien vähentäminen edellyttäisi monin paikoin kuivatus- ja viljelymenetelmien muuttamista. Lisäksi tulisi arvioida miten ja minne toimenpiteet olisi kustannustehokkainta kohdentaa. Tähän tulokseen voidaan päästä vain laajapohjaisen ja osallistavan prosessin kautta, jossa otetaan huomioon luonnontieteellisten näkökohtien ohella myös sosio-ekonomiset seikat.

EU:n LIFE+-ohjelmasta myöntämä yhteensä 1,2 miljoonan euron rahoitus Suomen ympäristökeskuksen (SYKE) koordinoimalle hankkeelle "Happamien sulfaattimaiden ympäristöriskien vähentäminen -sopeutumiskeinoja ilmastomuutokseen" (CATERMASS) edistää osaltaan HS-maiden riskien hallintaa. Hanke toteutetaan vuosina 2010-2012 ja sen kokonaisbudjetti on noin 2,8 miljoonaa euroa. Muut toteuttajaorganisaatiot ovat Länsi-Suomen ympäristökeskus (tuleva Etelä-Pohjanmaan elinkeino-, liikenne- ja ympäristökeskus), Geologian tutkimuskeskus, Maa- ja elintarviketalouden tutkimus- 
keskus, Riista- ja kalatalouden tutkimuslaitos, Åbo Akademi ja Helsingin yliopisto. Yhteistyötahoina hankkeen toteutuksessa ovat myös Österbottens svenska producentförbund, ProAgria ja PohjoisPohjanmaan ympäristökeskus. Lisäksi hankkeeseen pyritään ottamaan mukaan laajasti länsirannikon jokineuvottelukunnissa mukana olevia sidosryhmiä ja aiheen parissa työskenteleviä asiantuntijoita. Hankkeen toimintakohteena ovat kaikki todennetut ja potentiaaliset happamien sulfaattimaiden vaikutuspiirissä olevat vesistöalueet. Hankkeen edistymisestä ja järjestettävistä koulutus- ym. tapahtumista tullaan tiedottamaan SYKEn verkkosivuilla (www.ymparisto.fi/syke/catermass).

\section{Kirjallisuus}

Fältmarsch, R., Åström, M. \& Vuori, K.-M. 2008. Environmental risks of metals mobilised from acid sulphate soils in Finland: A literature review. Boreal Environ. Res. 13:444-456.

Lin, C., Wu, Y., Lu, W., Chen, A. \& Liu, Y. 2007. Water chemistry and ecotoxicity of an acid mine drainageaffected stream in subtropical China during a major flood event. J. Haz. Materials 142:199-207.

Rosen, J., Pike, C.S., Golden, M.L. \& Freedman, J. 1978. Zinc toxicity in corn as a result of a geochemical anomaly. Plant and Soil 50:151-159.

Silander, J., Vehviläinen, B., Niemi, J, Arosilta, A., Dubrovin, T., Jormola, J., Keskisarja, V., Keto, A., Lepistö, A., Mäkinen, R, Ollila, M., Pajula, H., Pitkänen, H., Sammalkorpi, I., Suomalainen, M. \& Veijalainen, N. 2006. Climate change adaptation for hydrology and water resources. FINADAPT Working Paper 6, Finnish Environment Institute Mimeographs 336, Helsinki, 52 pp.

Vuori, K.-M. 2009. Pintavesiemme tila uusien luokitteluperusteiden valossa. Vesitalous 2/2009: 11-15.

Österholm P, Åström M. 2008. Meteorological impacts on the water quality in the Pajuluoma acid sulphate area, W. Finland. Appl. Geochem. 23: 1594-1606. 